\title{
Neurocognitive Functioning in Glioblastoma Multiforme Patients during Radiotherapy Plus Concomitant and Adjuvant Temozolomide: A Case Series
}

\author{
Slovackova $\mathbf{B}^{1}$, Zirko $\mathbf{R}^{1}$ and Slovacek $\mathrm{L}^{2^{*}}$ \\ ${ }^{1}$ Department of Psychiatry, Charles University Hospital and Faculty of Medicine, Hradec Kralove, Czech Republic \\ ${ }^{2}$ Department of Oncology and Radiation Therapy, Charles University Hospital and Faculty of Medicine, Hradec Kralove, Czech Republic
}

*Corresponding author: Ladislav Slovacek, Department of Oncology and Radiation Therapy Charles University Hospital and Faculty of Medicine in Hradec Králové, Sokolska 581, 50005 Hradec Kralove, Czech Republic, Tel: 00420495832176; Fax: 00420495832081; E-mail: ladislav.slovacek@seznam.cz

Rec date: May 18, 2014, Acc date: June 2, 2014, Pub date: June 10, 2014

Copyright: ( 2014 Slovacek L, et al. This is an open-access article distributed under the terms of the Creative Commons Attribution License, which permits unrestricted use, distribution, and reproduction in any medium, provided the original author and source are credited.

\begin{abstract}
Background: Glioblastoma Multiforme (GBM) belongs to the most aggressive brain tumours with limited therapeutic options. In the clinical presentation often dominate the mental changes (memory loss, impaired speech, changes in personality and temperament). The authors evaluate in a pilot study the neurocognitive function of patients with GBM.
\end{abstract}

Patients and Methods: The evaluation of neurocognitive function had been performed during 2009-2010 in eleven patients with GBM ( 9 women, 2 men) with a mean age of 56.8 years (age range 45-72). The assessment of neurocognitive functions was performed by clinical neuropsychologist using the methods sensitive for cognitive deficit.

Results: Because of a limited set of patients and an insufficient number of schedule check-ups (caused by severe tumour progression) the results could not be statistically evaluated. Due to these circumstances, the results of a pilot project are presented in the form of a case series. There are presented the results of three patients with different localization of GBM and with different type of neurosurgical intervention (total resection, subtotal resection and stereotactic biopsy).

Conclusion: The diagnosis of cognitive deficit can be based on careful assessment of personal medici history, present symptoms and physical examination. Laboratory tests and paging technique help by the detection of secondary cognitive changes. Targeted examination of cognitive function relies in use of various neuropsychological tests. To monitor developments and changes in cognitive functions in patients with GBM the following battery of neuropsychological tests has shown helpful information: Addenbrooke's Cognitive Examination, Trail Making Test, Rey-Osterrieth Complex Figure and Verbal Fluency Test. It seems that this battery of neuropsychological tests is suitable for repeated long-term monitoring of cognitive function in cancer patients undergoing radiotherapy of brain.

Keywords: Malignant glioma; Glioblastoma; Neurocognitive function; Quality of Life

\section{Introduction}

Glioblastoma Multiforme (GBM) accounts for approximately $15-20 \%$ of all primary brain tumours [1]. The incidence is estimated at 3-4 new cases per 100000 people per year. GBM may manifest in persons of any age, but it affects adults preferentially, with a peak incidence at $45-75$ years (more than $80 \%$ of patients are older than 50 years). Histopathology of GBM is characterized by very rapid and infiltrative growth, high mitotic activity, extreme cellular atypia. Tumour stroma is rich in blood vessels and common findings are hemorrhages and areas of necrosis. The tumour usually affects a large portion of brain tissue [2]. GBM is one of the most aggressive brain tumours with limited therapeutic options [1-3]. GBM is characterized by a high degree of genetic and histomorphologic variability. Clinical manifestations of GBM can be divided into general and specific depending on the type, location and size of tumour. Cephalea is the most common symptom. It is often more pronounced in the morning and decreases during the day. The headache is more pronounced during various activities like sneezing and changes of body position, but it is not rare that the pain wakes sleeping patient. The tumour may primarily manifest by epileptic seizure or confusion (in about $1 / 3$ of patients). Another common symptom for all patients with this kind of tumour is mental changes. There can be seen a shortage of memory, speech disturbances or changes in personality and temperament $[3,4]$. The increased intracranial pressure caused by the tumour can lead to impaired sight. When the tumour localization is in the brain stem, the basic life functions are at risk. From the manifestation of symptoms we can deduce the tumour localization. Swallowing of food can be impaired (dysphagia) if the neural network coordinating swallowing is affected. Reading, writing, voluntary movement are affected if the cerebral hemispheres are involved, changes in behaving and psyche if the tumour is located in frontal lobe and unilateral blindness and aphasia if the tumour infiltrates the occipital lobe. Diagnosis is usually confirmed by non-invasive imaging. The crucial role has Magnetic Resonance Imaging (MRI) and its extended version including spectral MRI (measures metabolism of the affected area in the brain; optimal for differentiation of the tumour and radiation necrosis), functional MRI (gathers information on blood flow within tumours related to neural activity, gives more information about the tumour and the 
function of surrounding normal brain issue), perfusion MRI (provides a relative and/or absolute measurement of the parameters of cerebral microvascularisation; important in determining tumour grading ) and diffusion MRI (it shows connections between brain regions). GBM typically appears as ringenhancing lesion with centrally stored necrotic areas and surrounding edema. The definitive diagnosis requires stereotactic biopsy or craniotomy with tumour resection and histological verification. For children the cytogenetic examination should be added. To obtain a tissue from the brain stem can be difficult or impossible. The definitive diagnosis has to be then verified by the extended version of MRI. Histological examination should include also the evaluation of proliferation marker Ki-67. Its high value indicates more risk for disease progression, low value for pseudoprogression. In the case of high-grade gliomas, there is advised to test the MGMT (methylguanine DNA methyltransferase) promoter methylation status as a potential independent prognostic factor for survival in patients with GBM treated with alkylating agents and its association with a higher rate of clinical response [5]. The treatment of GBM is multimodal, i.e. neurosurgical resection, external-beam radiotherapy, systemic chemotherapy, or their combination with improvement of overall survival [5-7]. Nowadays the targeted therapy is used with promising results for bevacizumab, cediranib and imatinib $[5,8]$. The therapy of GBM should be determined individually in order to ensure the highest possible quality of care and life for the patient.

\section{Patients and Methods}

The pilot project took place between 2009-2010 in Cancer Center of Charles University Hospital in Hradec Kralove, Czech Republic. The pilot project dealt with the evaluation of neurocognitive functioning and their changes in patients with GBM undergoing radiotherapy with/without concomitant and adjuvant temozolomide. The following basic hypothesis was set: "Patients with GBM have neurocognitive dysfunction depending on the localization, staging and grading of the disease. During the radiotherapy with/without concomitant temozolomide we can expect mild or moderate cognitive impairment. With a longer interval from therapy we can expect on the contrary improvement in cognitive functions." Secondary objective of the pilot project was to verify the suitability of neurocognitive tests in clinical practice for screening of cognitive function in patients with GBM during their treatment, with regard to their difficulty, time demands, administrativ and possibility of retests.

From the 1st January 2009 to the 30th June 2010 the evaluation of neurocognitive functioning had been performed in eleven patients with GBM ( 9 women, 2 men) with a mean age of 56.8 years (age range 45-72). Four patients underwent total resection of GBM, subtotal resection was performed in five patients and two patients had stereotactic biopsy. The localization of GBM was in six patients in the frontal lobe, in two patients in fronto-temporal area, in two patients in fronto-parietal area and in one patient in parieto-occipital area. All patients underwent postoperative external-beam radiotherapy with a $25-\mathrm{mm}$ margin at a dose of $50 \mathrm{~Gy}$ in 25 fractions and a boost to the tumour with a $15-\mathrm{mm}$ margin at a dose of $10 \mathrm{~Gy}$ in five fractions with chemotherapy of temozolomide at dose $75 \mathrm{mg} / \mathrm{m} 2$.

The cognitive function affected by radiation are related to frontalsubcortical white matter dysfunction and include impairments of learning and memory, processing speed, executive function and fine motor control [9]. The following battery of neuropsychological tests has been used, because of their known sensitivity to cognitive deterioration particularly in mentioned cognitive domains [10-12]:

1. Addenbrooke's Cognitive Examination (ACE-R) is a battery of tasks that assesses five cognitive domains, namely attention/ orientation, memory, verbal fluency, language and visuospatial abilities. Total score is 100 , higher scores indicates better cognitive functioning. The Mini Mental State Examination (MMSE) is integrated into ACE-R $[13,14]$.

2. Trail Making Test (TMT) is a test of visual attention and task switching. The task requires a subject to connect-the-dots of 25 consecutive targets on a sheet of paper. Two versions are available: A, in which the targets are all numbers $(1,2,3$, etc.), and $B$, in which the subject alternates between numbers and letters (1, A, 2, B, etc.). Result is reported as the number of seconds required to complete the task; therefore, higher scores reveal greater impairment.

3. Rey-Osterrieth Complex Figure (ROCF) is a test assessing the spatial perception, visual memory, drawing, planning and constructional abilities. The examinees are asked to reproduce a complicated line drawing, first by copying and then from memory. The test is not timed, but the length of time needed to copy the figure is observed. Once the copy is complete, the stimulus figure and the examinee's copy are removed from view and after a short delay (3 minutes), the examinee is asked to reproduce the figure from memory. Examinees are not told beforehand that they will be asked to draw the figure from memory so this is the test of incidental or implicite memory. Each copy is scored for the accurate reproduction and placement of 18 specific design elements.

4. Digit Span (DS) is a partial test of short-term verbal memory and working memory. The examinee is asked to repeat a list of numbers as dictated by the examiner. Higher scores mean better verbal memory span.

5. Verbal Fluency Test (VFT) is test in which participants have to say as many words as possible from a category in a given time (usually 60 seconds). This category can be semantic, such as animals in our case, or phonemic, such as words that begin with specific letter (N,P,K in our case). It is used as a measure of executive functions, fluency of thinking and language abilities.

6. Continuous Performance Test (CPT) is a computer-based task designed to measure a person's ability to withhold responses to infrequent and unpredictable stimuli during a period of rapid and rhythmic responding to frequent stimuli. It measures the sustained and selective attention and impulsivity through scores of time reaction, accuracy and stability of reaction.

In summary, we used one complex screening method (ACE-R), Two Graphomotoric Tests (TMT, ROCF), two verbal tests (DS, VFT) and one computer-administered test (CPT). The total examination time took about 1 hour.

The schedule of examination during the pilot project was following: 1. before radiotherapy with chemotherapy (performed in all 11 patients), 2. immediately after radiotherapy with chemotherapy (performed in 7 patients), 3. one month from finishing the adjuvant treatment (performed in 5 patients), 4. three months after finishing the adjuvant treatment (performed in 1 patient, 5. six months after finishing the treatment (performed in 1 patient). Due to the rapid progression of GBM and related alterations of somatic and mental status, only one patient underwent the whole planned schedule of examinations. 
Citation: Slovackova B, Zirko R and Slovacek L (2014) Neurocognitive Functioning in Glioblastoma Multiforme Patients during Radiotherapy

Page 3 of 7

\section{Results}

The results of this project cannot be statistically evaluated for two reasons: 1. small set of patients, 2. insufficient number of control examinations (due to rapid progression of tumour). That's why we present the results of our pilot project in the form of a case series. We present results of three patients with different localization of GBM and with different type of neurosurgical intervention (total resection, subtotal resection and stereotactic biopsy). Baseline features of GBM patients of a case series are stated in Table 1.

\begin{tabular}{|c|c|c|c|c|c|c|}
\hline $\begin{array}{l}\text { No. of case } \\
\text { report }\end{array}$ & Age & Sex & Location of tumor & $\begin{array}{l}\text { Karnofsky Preformance } \\
\text { Status }\end{array}$ & Resection status & Radiation dose/boosts plus temozolomide \\
\hline $\begin{array}{l}\text { Case report } \\
\text { No. I }\end{array}$ & 64 & female & $\begin{array}{l}\text { right frontal lobe with } \\
\text { infiltration of corpus callosum. }\end{array}$ & $100 \%$ & total resection & $\begin{array}{l}\text { postoperative external-beam radiotherapy } \\
\text { with a } 25-\mathrm{mm} \text { margin at a dose of } 50 \mathrm{~Gy} \text { in } \\
25 \text { fractions and a boost to the tumour with } \\
\text { a } 15 \text {-mm margin at a dose of } 10 \mathrm{~Gy} \text { in five } \\
\text { fractions with chemotherapy of } \\
\text { temozolomide at dose } 75 \mathrm{mg} / \mathrm{m} 2\end{array}$ \\
\hline $\begin{array}{l}\text { Case report } \\
\text { No. II }\end{array}$ & 49 & female & left frontotemporal lobe & $100 \%$ & subtotal resection & $\begin{array}{l}\text { postoperative external-beam radiotherapy } \\
\text { with a } 25-\mathrm{mm} \text { margin at a dose of } 50 \mathrm{~Gy} \text { in } \\
25 \text { fractions and a boost to the tumour with } \\
\text { a } 15-\mathrm{mm} \text { margin at a dose of } 10 \mathrm{~Gy} \text { in five } \\
\text { fractions with chemotherapy of } \\
\text { temozolomide at dose } 75 \mathrm{mg} / \mathrm{m} 2\end{array}$ \\
\hline $\begin{array}{l}\text { Case report } \\
\text { No. III }\end{array}$ & 64 & female & $\begin{array}{l}\text { fronto-parietal area left near to } \\
\text { the falx cerebri }\end{array}$ & $100 \%$ & $\begin{array}{l}\text { cannot } \\
\text { resected }\end{array}$ & $\begin{array}{l}\text { postoperative external-beam radiotherapy } \\
\text { with a } 25-\mathrm{mm} \text { margin at a dose of } 50 \mathrm{~Gy} \text { in } \\
25 \text { fractions and a boost to the tumour with } \\
\text { a } 15-\mathrm{mm} \text { margin at a dose of } 10 \mathrm{~Gy} \text { in five } \\
\text { fractions with chemotherapy of } \\
\text { temozolomide at dose } 75 \mathrm{mg} / \mathrm{m} 2\end{array}$ \\
\hline
\end{tabular}

Table 1. Baselines features of GBM patients of a case series.

\section{Case Report I}

64 years old patient with GBM, grade IV in frontal diagnosed in February 2009, underwent a total resection followed by postoperative radiotherapy with concomitant temozolomide at a dose of $75 \mathrm{mg} / \mathrm{m} 2$. The Karnofsky Performance Status (KPS) was assessed as $100 \%$. Preoperative MRI showed tumour expansion in right frontal lobe with infiltration of corpus callosum. Postoperative MRI showed small residual tumour $(16 \times 10 \mathrm{~mm})$ in the dorsal part of the resection cavity. Control MRI of the brain one month after finishing the chemoradiotherapy showed persisting residuum of GBM in the right frontal lobe. The deterioration of cognitive functions corresponding with mild stage of dementia had been already proven with neuropsychologist test before the postoperative chemoradiotherapy. In the course of each examination neuropsychological tests showed progressive worsening of cognitive functions (Table 2). There were no signs of depressive syndrome, psychotic disorder or sleep disorder. There was no need to use antipsychotics.

\begin{tabular}{|c|c|c|c|}
\hline & $\begin{array}{l}\text { before } \\
\text { CHRT }\end{array}$ & $\begin{array}{l}\text { after } \\
\text { CHRT }\end{array}$ & $\begin{array}{l}1 \mathrm{~m} \text {. after } \\
\text { CHRT }\end{array}$ \\
\hline Date of examination & 16.3.2009 & 16.4.2009 & 25.5 .2009 \\
\hline \multicolumn{4}{|l|}{ Global cognitive functioning } \\
\hline MMSE (score) & 23 & 20 & 18 \\
\hline ACE-R (score) & 67 & 62 & 53 \\
\hline \multicolumn{4}{|l|}{ Speed of processing } \\
\hline $\begin{array}{l}\text { Trail Making Test Part A (time in } \\
\text { seconds) }\end{array}$ & 102 & 119 & 144 \\
\hline
\end{tabular}

\begin{tabular}{|c|c|c|c|c|c|}
\hline \multicolumn{3}{|l|}{ (SD) } & -5.1 & -6.4 & -8.4 \\
\hline \multicolumn{6}{|c|}{ Language skills } \\
\hline \multicolumn{3}{|c|}{$\begin{array}{l}\text { Verbal Fluency Test Phonemic (sum of } \mathrm{N} \text {, } \\
\mathrm{K}, \mathrm{P} \text { words) }\end{array}$} & 10 & 6 & 0 \\
\hline \multicolumn{3}{|l|}{ (SD) } & -2.0 & -2.4 & -3 \\
\hline \multicolumn{3}{|c|}{$\begin{array}{l}\text { Verbal Fluency Test Semantic (number of } \\
\text { animals) }\end{array}$} & 10 & 7 & 3 \\
\hline \multicolumn{3}{|l|}{ (SD) } & -1.9 & $\mid-2.6$ & -3.4 \\
\hline \multicolumn{6}{|c|}{ Visual memory } \\
\hline \multicolumn{3}{|c|}{$\begin{array}{l}\text { Rey-Osterrieth Figure Immediate Recall } \\
\text { (points) }\end{array}$} & 18 & 11 & 7.5 \\
\hline \multicolumn{3}{|l|}{ (SD) } & -0.3 & -1.2 & -1.7 \\
\hline $\mathrm{SD}>0$ & $\begin{array}{l}\text { SD }(0 ; \\
-1)\end{array}$ & $\operatorname{SD}(-1 ;-2)$ & $\begin{array}{l}\text { SD }<-3 \\
D \\
( \\
- \\
2 \\
; \\
- \\
3 \\
)\end{array}$ & & \\
\hline
\end{tabular}

Table 2. The summary of results

\section{Case report II}

49 years old patient with GBM grade IV, localized in the left frontotemporal lobe, which was diagnosed in February 2009, underwent subtotal resection followed by postoperative radiotherapy 
Citation: Slovackova B, Zirko R and Slovacek L (2014) Neurocognitive Functioning in Glioblastoma Multiforme Patients during Radiotherapy Plus Concomitant and Adjuvant Temozolomide: A Case Series. J Integr Oncol 3: 118. doi:10.4172/2329-6771.1000118

Page 4 of 7

and concomitant temozolomide at a dose of $75 \mathrm{mg} / \mathrm{m} 2$. KPS was evaluated as $100 \%$. Preoperative CT examination revealed solid expansion with cystic structure $(45 \times 36 \mathrm{~mm})$ in the dorzo-frontally area left with large perifocal edema and shift of midline structures. Postoperative MRI showed residual tumour, which probably does not exceed $10 \%$ of the original volume. Control MRI one month after finishing of chemotherapy showed persisting residuum of GBM and MRI after 3 months showed in comparison with previous MRI constant size of residuum $(30 \times 30 \mathrm{~mm})$ but there was enormous progression of vasogenic edema. The psychological examinations during the therapy showed significantly better cognitive performance in comparison with the situation immediately after the operation. This improvement persisted even three months after finishing chemoradiotherapy. Six months after finishing chemoradiotherapy when the progression of vasogenic edema appeared on MRI, there was a significant decline in cognitive performance, which was even worse than it was immediately after surgery (Table 3 ). There were no signs of depressive syndrome, psychotic disorder or sleep disorder. There was no need to use antipsychotics.

\begin{tabular}{|l|l|l|l|l|}
\hline & $\begin{array}{l}\text { before } \\
\text { CHRT }\end{array}$ & $\begin{array}{l}\text { after } \\
\text { CHRT }\end{array}$ & $\begin{array}{l}1,5 \mathrm{~m} . \\
\text { after } \\
\text { CHRT }\end{array}$ & $\begin{array}{l}\text { 6 m. after } \\
\text { CHRT }\end{array}$ \\
\hline Date of examination & $\begin{array}{l}16.3 .200 \\
9\end{array}$ & $\begin{array}{l}16.4 .200 \\
9\end{array}$ & $\begin{array}{l}2.6 .200 \\
9\end{array}$ & $\begin{array}{l}6.10 .200 \\
9\end{array}$ \\
\hline
\end{tabular}

Global cognitive functioning

\begin{tabular}{|l|l|l|l|l|}
\hline MMSE (score) & 26 & 27 & 24 & 25 \\
\hline ACE-R (score) & 76.5 & 80.5 & 81 & 72.5 \\
\hline Speed of processing \\
$\begin{array}{l}\text { Trail Making Test Part A (time in } \\
\text { seconds) }\end{array}$ & 75 & 62 & 65 & 125 \\
\hline (SD) & -4.6 & -3.3 & -3.6 & -9.8 \\
\hline
\end{tabular}

Executive function

\begin{tabular}{|l|l|l|l|l|}
\hline $\begin{array}{l}\text { Trail Making Test Part B (time in } \\
\text { seconds) }\end{array}$ & Failed & 142 & 201 & Failed \\
\hline (SD) & & -2.9 & -5.2 & \\
\hline
\end{tabular}

\section{Language skills}

\begin{tabular}{|l|l|l|l|l}
\hline $\begin{array}{l}\text { Verbal Fluency Test Phonemic } \\
\text { (sum of N, K, P words) }\end{array}$ & 9 & 18 & 12 & 8 \\
\hline (SD) & -2.9 & -2.1 & -2.7 & -3.0 \\
\hline $\begin{array}{l}\text { Verbal Fluency Test Semantic } \\
\text { (number of animals) }\end{array}$ & 18 & 21 & 17 & 14 \\
\hline (SD) & -0.7 & -0.1 & -0.9 & -1.6 \\
\hline
\end{tabular}

Visuospatial and constructional abilities

\begin{tabular}{|l|l|l|l|l|}
\hline $\begin{array}{l}\text { Rey-Osterrieth Figure Copy } \\
\text { (points) }\end{array}$ & 27 & 29 & 31 & 22.5 \\
\hline (SD) & -2.7 & -1.9 & -1.2 & -4.4 \\
\hline Visual memory \\
$\begin{array}{l}\text { Rey-Osterrieth Figure Immediate } \\
\text { Recall (points) }\end{array}$ & 4 & 12.5 & 15 & 5 \\
\hline
\end{tabular}

\begin{tabular}{|l|l|l|l|l|l|l|}
\hline$(\mathrm{SD})$ & \multicolumn{2}{|l|}{} & -2.6 & -1.5 & -1.1 & -2.5 \\
\hline SD >0 & $\begin{array}{l}\text { SD } \\
(0 \\
-1)\end{array}$ & $;$ & $\begin{array}{l}\text { SD }(-1 ; \\
-2)\end{array}$ & $\begin{array}{l}\text { SD }(-2 ; \\
-3)\end{array}$ & SD $<-3$ & \\
& & & \\
\hline
\end{tabular}

Table 3. The summary of results

\section{Case Report III}

64 years old patient with GBM grade IV in the fronto-parietal area left near to the falx cerebri, which was diagnosed by navigated stereotactic biopsy in August 2009, underwent radiotherapy and concomitant temozolomide at a dose of $75 \mathrm{mg} / \mathrm{m} 2$. KPS was evaluated as $100 \%$. Preoperative brain MRI showed tumour expansion $(40 \times 30 \mathrm{~mm})$ with opacification and central necrosis. Control MRI one month after chemoradiotherapy showed a slight progression of the tumour, however, significant progression of necrosis. The patient suffered from insomnia and subdepression. The patient was commenced on mirtazapine $15 \mathrm{mg}$ per day and bromazepam 1,5-3 mg per day. There was no sign of cognitive deterioration right after stereotactic biopsy. Global cognitive performance stayed at similar level in each neuropsychological examination (according to ACE-R score). After the therapy there was observed a slight improvement in psychomotoric tempo and flexibility in a verbal fluency test (animals) and graphomotoric tasks in TMT A (Table 4).

\begin{tabular}{|c|c|c|c|}
\hline & $\begin{array}{l}\text { before } \\
\text { CHRT }\end{array}$ & $\begin{array}{l}\text { after } \\
\text { CHRT }\end{array}$ & $\begin{array}{l}1 \mathrm{~m} . \text { afte } \\
\text { CHRT }\end{array}$ \\
\hline Date of examination & $\begin{array}{l}11.9 .200 \\
9\end{array}$ & $\begin{array}{l}14.10 .200 \\
9\end{array}$ & $\begin{array}{l}13.11 .200 \\
9\end{array}$ \\
\hline \multicolumn{4}{|l|}{ Global cognitive functioning } \\
\hline MMSE (score) & 28.5 & 30 & 28 \\
\hline ACE-R (score) & 89.5 & 91 & 91 \\
\hline \multicolumn{4}{|l|}{ Speed of processing } \\
\hline Trail Making Test Part A (time in seconds) & 82 & 70 & 53 \\
\hline$(\mathrm{SD})$ & -3.5 & -2.6 & -1.2 \\
\hline
\end{tabular}

Executive function

\begin{tabular}{|l|l|l|l|}
\hline Trail Making Test Part B (time in seconds) & 178 & 242 & 226 \\
\hline (SD) & -2.2 & -3.9 & -3.5 \\
\hline
\end{tabular}

Language skills

Verbal Fluency Test Phonemic (sum of $\mathrm{N}$, $\mathrm{K}, \mathrm{P}$ words)

\begin{tabular}{|l|l|l|l|}
\hline K, P words) & 22 & 22 & 20 \\
\hline$(\mathrm{SD})$ & -1.1 & -1.1 & -1.2 \\
\hline $\begin{array}{l}\text { Verbal Fluency Test Semantic (number of } \\
\text { animals) }\end{array}$ & 17 & 19 & 23 \\
\hline$(\mathrm{SD})$ & -0.4 & 0 & +0.9 \\
\hline Visuospatial and constructional abilities & 31 & 33 & Not \\
\hline Rey-Osterrieth Figure Copy (points) & -0.3 & +0.1 & available \\
\hline (SD) & & &
\end{tabular}




\begin{tabular}{|c|c|c|c|c|c|}
\hline \multicolumn{6}{|c|}{ Visual memory } \\
\hline \multicolumn{3}{|c|}{$\begin{array}{l}\text { Rey-Osterrieth Figure Immediate Recall } \\
\text { (points) }\end{array}$} & 11.5 & 13.5 & Not \\
\hline \multicolumn{3}{|l|}{ (SD) } & -1.2 & -0.9 & available \\
\hline$S D>0$ & $\begin{array}{l}\text { SD } \\
-1)\end{array}$ & $\mathrm{SD}(-1 ;-2)$ & $\begin{array}{l}S D \quad(-2 ; \\
-3)\end{array}$ & $S D<-3$ & \\
\hline
\end{tabular}

Table 4. The summary of results

\section{Discussion}

Radiotherapy (RT) is an important treatment modality of primary and metastatic tumours of the central nervous system [15-17]. But the brain and spinal cord may also be affected by radiation during the treatment of head and neck cancers, lung cancer, breast cancer or malignant lymphomas. The use of RT is nowadays used also in nonmalignant diseases such as vascular anomalies, epilepsy, neuralgia, tremor and other neurological diseases [15-17]. The posibility of damage of nerve tissue is the limiting factor for radiation and its total administrated dose [15,17]. To the risk factors influencing the occurrence of postirradiation tissue damage belongs: a) administration of too high cumulative doses per fraction greater than 1,8 to $2,0 \mathrm{~Gy}$ (in adults) and the total size of irradiated tumour volume, b) localization of the tumour or lesion, c) comorbidities such as arterial hypertension, diabetes mellitus, vascular and autoimmune diseases, infection, etc., d) the use of medications or drugs that can be toxic to the nervous systém (alcohol, addictive substances, immunosuppressant), e) age, f) and some chemotherapeutics [18].

The central nervous tissue reacts to radiation with dynamic process that can lead to cells death. The radiation starts a complex cellular reaction. With help of cytokines and growth factors produce from irradiated tissue it comes to progression secondary reactive process that results in persistent oxidative stress [17]. But the detailed way of immune changes as a reaction to radiation is not yet clarified $[17,18]$. The development of tissue damage leading to the necrosis includes: 1 . Vascular injury - in an acute phase the radiation disrupts hematoencephalic barrier. This leads to subsequent vascular changes like transient vasodilatation and changes in capillary permeability and at the end the vasogenic edema arises. In chronic phase there are dominating changes in the vascular endothelium like telangiectasia. All these changes lead at the end to the irreversible vascular damage (fibrosis and hyalinization) with subsequent thrombosis, infarction and necrosis [15]. 2. Damage of glial cells and white matter oligodendrocytes are damaged earlier than neurons because of higher sensitivity to radiation. There is successive loss of cellular components in white matter manifested by reducing of the brain volume [16]. 3 . Impairment of the fibrinolytic enzyme system - in the irradiated tissue there is lack of tissue plasminogen activator and excess of urokinase plasminogen activator. This disbalance affects negatively the vascular wall and brain tissue resulting in cytotoxic edema and tissue necrosis [15]. The radiation injury of brain can be divided from the time perspective as acute (days after irradiation), early (weeks and months after irradiation) and late (months to years) [18,19]. The acute radiation injury is characterized with cephalea, nausea, vomiting, fever, worsening of previous focal symptoms, and impaired consciousness. It is supposed that in acute phase there is a brain edema leading to disruption of hematoencephalic barrier. Symptoms of early radiation injury do not differ too much from symptoms, which were present before own radiation. The so called somnolence syndrome representing by subacute encephalopathy can be seen in patient with prophylactic cranial irradiation. The symptoms usually fade away spontaneously. There are two main types of brain damage arising in late phase: a) diffuse encephalopathy with demyelinating and capillary endothelium changes, with symptoms like cognitive dysfunction, dementia, apraxia and incontinence and b) focal necrosis with focal symptoms. The brain tumour can manifestate among others in form of so called psychopathological symptoms. The variety of psychological symptoms is large, including for example pseudoneurastenic syndrome, qualitative impairment of consciousness (delirium), cognitive disorders, emotional malfunctions (anxiety, depression, mania), behavioural alteration (agitation, aggression), and personality changes. Among cognitive functions we include practical skills, language skills, attention, memory and executive functions. Alteration of cognitive function may have different intensities from mild (mild cognitive impairment) to severe (dementia). The factors influencing the cognitive function in patients with GBM except of tumour itself are: 1. emotional factors (stress, prolonged depression), 2. side effects of medication (analgesics and anti-emetics with central effects, corticosteroids), 3. overall body discomfort and complications of cancer therapy (anemia, pain, fatigue, infections, nutritional deficiencies, sleep deficit), 4. irradiation of cranium, 5. other factors (for example extent of surgery). In patients with glioma the preservation of cognitive performance is an independent positive prognostic factor of survival. The etiology of neurocognitive deterioration can be also related to delayed radiationinduced leukoencephalopathy with cognitive dysfunction leading in some cases to severe stage of dementia. At first the memory dysfunction arises. It starts with failure of learning new things and forgetting of new information. There are deficits in executive function located in frontal lobe and there is successive lose of fine motoric coordination $[9,18,20]$. The first signs of neurocognitive deterioration can be already seen 3-12 months after irradiation of the brain and it progress slow in time. The leukoencephalopathy is described on CT and MRI as combination of cortical atrophy and enlarging ventricles. Microscopic changes are associated with tissue necrosis [18] with diverse picture from multiple small deposits of necrosis spread in the white matter, over difuse axonal loss and demyelination, to diffuse vacuolization (spongiosis) in the white matter $[18,20,21]$. The development of leukoencephalopathy with dementia is a negative prognostic factor of long term survival of the originally treated tumour $[18,22]$.

In our pilot project we detect a big variability in cognitive functions in the first assessment (before radiotherapy). The reason of this variability is with high probability associated with different way and invasiveness of selected neurosurgery intervention. Patients, who underwent the most radical neurosurgery, had the worst results. The average score in ACE- $R$ test in a group of 4 patients with complete resection was 75.5 points, in group of 5 patients with partial or subtotal resection 84.1 points and in group of 2 patients with stereotactic biopsy 87.8 points. For any similar monitoring of patients in the future it would be appropriate to implement the first neuropsychological assessment before the surgery. This would then allow distinguishing the negative impact of radiotherapy with/without chemotherapy from the traumatic impact of neurosurgical intervention. The different impact or combination of above mentioned factors is, together with tumour progression and localization of GBM, a reason of different progress of cognitive functions during the follow up period. In the first case there is a continuous worsening of cognitive performance regardless of treatment within 3 months. In the second case there is an improvement in cognitive performance immediately 
after radiotherapy lasting for 1 and half months and then subsequent deterioration after half a year (it is the same time of progression of vasogenic edema). And in the third case report the patient maintain the cognitive performance at a similar level during three monitored months. In terms of the suitability of each neuropsychological test, the Addenbrooke's Cognitive Test showed the best applicability. This test is suitable mainly for the moderate and severe impairment of cognitive functions (see Tab. 1-3). The MMSE alone does not measure cognitive functions that are likely to be affected by radiation therapy [23]. Compared to the MMSE repeated using of the ACE-R provides more accurate evaluation with a finer scoring scale and so it has also bigger potential to follow the progress and deterioration of cognitive function in time. Another advantage of ACE-R is the evaluation of multiple cognitive domains allowing focusing on individual cognitive rehabilitation. On the contrary the ACE-R is not suitable for patient with good cognitive performance or only a mild deficit. For them is too easy and it does not show any significant changes in score during the treatment. We have approved that the inclusion of more sensitive tests like Trail Making Test, Verbal Fluency Test and Rey-Osterrieth Complex Figure can help to detect even slight dysfunctions and changes in cognitive performance.

The Digit Span results show low variability of score and big sensitivity to fluctuations in attention and other short-term situational influences. In our pilot project the DS results does not show any significant trend during the repeated examinations. The use of DS has not expected benefit. In terms of practical application we have ceased from using of the Continuous Performance Test. The realisation was for patient too difficult and exhausting. The other mason was the need for a computer and complication with its use.

\section{Conclusion}

The diagnosis of cognitive dysfunction can be based on careful assessment of personal medical history, clinical symptoms and physical examination. Laboratory and imaging examinations are primarily used to detect secondary cognitive changes. The specific tests focusing on cognitive function is then secured by neuropsychological tests. We compile the battery of neuropsychological tests to monitor developments and changes in cognitive performance in patients with GBM (Addenbrooke's Cognitive Test, Trail Making Test, Verbal Fluency Test and Rey-Osterrieth Complex Figure). This battery of tests can be recommend generally for repeated long-term monitoring of cognitive function in cancer patients undergoing radiotherapy of the brain. The use of scales and specific neuropsychological battery allows in clinical praxis: 1. earlier detection of cognitive dysfunction, 2. objective and reproducible monitoring of progress of dysfunction in time, 3. opportunity to specify the way of rehabilitation of cognitive functions. It is particularly suitable when the patient is treated by several medical specialists because it facilitates communication between them. Currently there are no specific treatments possibilities for cognitive dysfunction in malignant tumour diseases. The cognitive function can be affected non-specifically by using of nootropics. Indirectly it can be positively affect by avoiding of using the medication with too sedating drugs and drugs with central anticholinergic effect. It is also necessary to have in mind the possible presence of depressive pseudodementia, which can be treated with antidepressants. Last but not least it is important to support the implementation of cognitive training in hospital in patients with proven cognitive deficit.

\section{Acknowledgements}

Supported by MH CZ-DRO (UHHK, 00179906).

\section{References}

1. Guckenberger M, Mayer M, Buttmann M, Vince GH, Sweeney RA, et al. (2011) Prolonged survival when temozolomide is added to accelerated radiotherapy for glioblastoma multiforme. Strahlenther Onkol 187: 548-554.

2. Kopecky J, Priester P, Slovácek L, Petera J, Kopecký O, et al. (2010) Aplastic anemia as a cause of death in a patient with glioblastoma multiforme treated with temozolomide. Strahlenther Onkol 186: 452-457.

3. Fabrini MG, Perrone F, De Franco L, Pasqualetti F, Grespi S, et al. (2009) Perioperative high-dose-rate brachytherapy in the treatment of recurrent malignant gliomas. Strahlenther Onkol 185: 524-529.

4. Fokas E, Wacker U, Gross MW, Henzel M, Encheva E, et al. (2009) Hypofractionated stereotactic reiradiation of reccurent glioblastomas. A beneficial treatment option after high-dose radiotherapy?. Strahlenther Onkol 185: 235-240.

5. Lakomy R, Burkon P, Burkonová D, Jancálek R (2010) [New therapeutic options in therapy of glioblastoma multiforme]. Klin Onkol 23: 381-387.

6. Kocher M, Frommolt P, Norbert Sk, et al. (2008) Randomized study of postoperative radiotherapy and simultaneous temozolomide without adjutant chemotherapy for glioblastoma. Strahlenther Onkol 184: 572-579.

7. Kocher M, Kunze S, Eich HT, Semrau R, Muller RP (2005) Efficacy and toxicity of postoperative temozolomide radiochemotherapy in malignant glioma. Strahlenther Onkol 181: 157-163.

8. Oertel S, Krempien R, Lindel K, Zabel A, Milker-Zabel S, et al. (2006) Human glioblastoma and carcinoma xenograft tumors treated by combined radiation and imatinib (Gleevec). Strahlenther Onkol 182: 400-407.

9. Meyers CA, Geara F, Wong PF, Morrison WH (2000) Neurocognitive effects of therapeutic irradiation for base of skull tumors. Int J Radiat Oncol Biol Phys 46: 51-55.

10. Mitrushina M, Boone KB, Razani J, D'Elia LF (2005) Handbook of Normative data for Neuropsychological Assessment. (2nd Edn.), Oxford University Press, New York.

11. Preiss M, Laing H, Rodriguez M (2002) Neuropsychological Battery Prague Psychiatric Center. clinical examination of basic cognitive functions. (2nd Edn.), prepracovane vydani.

12. Balzano J, Chiaravalloti N, Lengenfelder J, Moore N, DeLuca J (2006) Does the scoring of late responses affect the outcome of the paced auditory serial addition task (PASAT)? Arch Clin Neuropsychol 21: 819-825.

13. Mioshi E, Dawson K, Mitchell J, Arnold R, Hodges JR (2006) The Addenbrooke's Cognitive Examination Revised (ACE-R): a brief cognitive test battery for dementia screening. Int J Geriatr Psychiatry 21: 1078-1085.

14. Hummelova-Fanfrdlova Z, Rektorova I, Sheardova K, Bartos A, Línek V, et al. (2009) Ceska adaptace Addenbrookského kognitivního testu. Ceskoslovenská psychologie 53: 376-588.

15. Kumar AJ, Leeds NE, Fuller GN, Van Tassel P, Maor MH, et al. (2000) Malignant gliomas: MR imaging spectrum of radiation therapy- and chemotherapy-induced necrosis of the brain after treatment. Radiology 217: 377-384.

16. Langleben DD, Segall GM (2000) PET in differentiation of recurrent brain tumor from radiation injury. J Nucl Med 41: 1861-1867.

17. Tofilon PJ, Fike JR (2000) The radioresponse of the central nervous system: a dynamic process. Radiat Res 153: 357-370.

18. Zapletalova O (2003) Neurologicke komplikace protinadorove lecby. Neurol Pro Praxi 5: 249-252. 
Citation: Slovackova B, Zirko R and Slovacek L (2014) Neurocognitive Functioning in Glioblastoma Multiforme Patients during Radiotherapy Plus Concomitant and Adjuvant Temozolomide: A Case Series. J Integr Oncol 3: 118. doi:10.4172/2329-6771.1000118

Page 7 of 7

19. Stupp R, Mason WP, van den Bent MJ, Weller M, Fisher B, et al. (2005) Radiotherapy plus concomitant and adjuvant temozolomide for glioblastoma. N Engl J Med 352: 987-996.

20. Vigliani MC, Duyckaerts C, Huaw JJ, Poisson M, Magdelenat H, et al. (1999) Dementia following treatment of brain tumours with radiotherapy administered alone or in combination with nitrosoureaa-based chemotherapy: A clinical and pathological study. J Neurooncol 41: 137-149.

21. Surma-aho O, Niemelä M, Vilkki J, Kouri M, Brander A, et al. (2001) Adverse long-term effects of brain radiotherapy in adult low-grade glioma patients. Neurology 56: 1285-1290.
22. Postma TJ (2002) Neurological complications of cancer therapy. Neurooncology and neuroimmunology. 6th Congres of the European Federation of Neurological Societies, October 26-29.

23. Meyers CA, Wefel JS (2003) The use of the mini-mental state examination to assess cognitive functioning in cancer trials: no ifs, ands, buts, or sensitivity. J Clin Oncol 21: 3557-3558. 